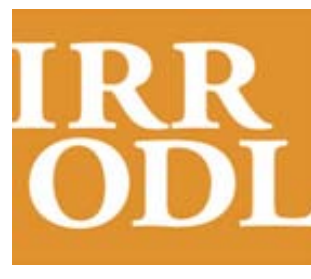

International

Review of

Research in Open and Distance

Learning

Vol. 12.2

February - 2011

\section{Head of Gold, Feet of Clay: The Online Learning Paradox}

\author{
Michael Power and Anthony Gould-Morven
}

Laval University, Canada

\begin{abstract}
Although online learning (OL) is becoming widely accessible and is often viewed as cuttingedge, the actual number of regular faculty participating in this form of teaching remains small. Moreover, OL, despite its growing recognition, is often associated with high rates of student dissatisfaction and isolation, withdrawal, and attrition. Furthermore, although administrators typically champion support of OL, they often seem unable or unwilling to marshal the necessary financial, human, and technological resources to produce high-quality course materials and to effect efficient course delivery. In short, online learning seems paradoxically to be both booming and busting simultaneously. It is expanding supply yet hitting similar obstacles that distance education encountered generations earlier. Under these circumstances, OL is unlikely to become mainstream without a major redirection. This article applies economic principles and concepts to OL. The revised conceptualization posits that an understanding of stakeholder priorities is the key to improved online course design and delivery.
\end{abstract}

Keywords: Online learning; core faculty; obstacles; push and pull; blended online learning design 


\section{Introduction}

Online learning has a "head of gold" and is sometimes touted as the key to better higher education (HE). This image comes mostly from its potential for large numbers of low unit-cost enrolments (Duderstadt, Atkins, \& Van Houweling, 2002; Pittinsky, 2003). On the other hand, online learning appears to have what we describe as "feet of clay" because it has not been widely embraced by mainstream academia. The reasons for low levels of uptake of this form of course delivery appear to center on perceptions of quality (Carr-Chellman, 2005; Noble, 2001) although they may be more complex. Nonetheless, in the face of such disparate influences, online learning is creeping into many centers of HE (Allen \& Seaman, 2008), although much of this growth is being managed by using contract faculty or adjuncts (Bedford, 2009; Sammons \& Ruth, 2007), whereas the majority of core faculty continue to deliver courses using a conventional lecture-hall format (OECD, 2005). This article is about paradoxes in online learning. It associates the major issues in OL with the main stakeholders and addresses perceptions of accessibility, quality, and efficiency, proposing a new way of reconciling the competing priorities of various stakeholders.

\section{From Distance Education to Online Learning: Stakeholder Perspectives}

Distance education, as a field, was founded for the purpose of creating and promoting greater social justice and equity. (Burge, 2008)

Distance education (DE) has a long and noble past. Some suggest that Saint Paul was one of the first-documented distance educators with his Corinthian correspondence. In more modern times, Pitman's "penny post" initiative in the mid-1800s and the University of London's correspondence education starting in 1858 are often seen as the modern beginning of this form of learning (Moore \& Kearsley, 2005). In the 20th century, DE made progress in adapting to learner needs and prevailing social and technological conditions. It has greatly influenced developments in educational technology and has emerged as a credible strategy for making learning more efficient and accessible without compromising quality (Bertrand, 2009; Daniel, Kanwar, \& UvalicTrumbic, 2009).

Online learning (OL), be it in the form of a new generation of DE (Anderson, 2008), a departure from DE (Garrison, 2009) or even a new paradigm for teaching and learning (Harasim, Hiltz, Teles \& Turoff, 1995), is advancing rapidly (Allen \& Seaman, 2008). For current purposes, we define OL as an essentially Internet-based, asynchronous type of distance education (Maeroff, 2003). It typically entails institutions providing instructional materials and support to students who are involved in flexible learning on a 24/7 basis (Bullen \& Janes, 2007; Collis \& Moonen, 2002).

The watershed U.S. Department of Education (2009) meta-analysis study reasserted the growing popularity of OL and provided empirical evidence of its relative effectiveness compared to traditional education. The report emphasized, in particular, the effectiveness of blended learning approaches that create complete and rich learning environments and compel students to learn. Despite such potential, OL is often developing, at the university level, without the full 
involvement of regular, core faculty (Sammons \& Ruth, 2007; Bedford, 2009), highlighted by the tendency to use contract faculty to deliver courses online. "As tenured or full-time faculty have been unable to fulfill these roles due to workload or resistance, organizations are more frequently turning to adjuncts to meet the needs of their online learners” (Bedford, 2009).

Stakeholders in the learning process, such as faculty, students and administrators, appear to have different reasons for adopting or resisting OL. For example, the huge increase in interest in OL has not always been synonymous with wide-scale adoption by HE institutions because of various hurdles and obstacles (Orr, Williams \& Pennington, 2009). Core faculty are often hesitant about participating because they fear it will add to their workload, diminish quality, or compromise intellectual property (Blin \& Munro, 2008; Maguire, 2005). Dreyfus (2001) refers to feelings of "disembodiment" and "alienation" on the part of faculty, whereas Shea, Fredericksen, Pickett, \& Pelz (2005) state that "[p]art of the explanation for the limited use of online teaching and learning is its incompatibility with the teaching styles of many professors.” Sammons \& Ruth (2007) add: "So the new 24/7 professor who is dragged from a traditional classroom into cyberspace may not be able to adjust."

Insofar as students are concerned, there has been a large increase in online course enrolments, especially in North America (OECD, 2005). However, there remains a fairly widespread perception that this form of course delivery is not only second-rate (Noble, 2001), but working against the democratization of HE (Carr-Chellman, 2005), and possibly representing a strategy for pushing a commercialization agenda (Bok, 2003). Furthermore, online students often feel alone and isolated, phenomena linked to unsustainably high rates of withdrawal and drop-out (Morgan \& Tam, 1999; Berge \& Huang, 2004). Research has highlighted other deficiencies of asynchronous courses. These include delayed feedback and lack of immediacy (Schullo et al., 2005), student isolation (Ludwig-Hardman \& Dunlap, 2003), inadequate social context (Vonderwell, 2003), and a lack of learner community support (Garrison \& Archer, 2007).

The third stakeholder in OL, administrators, is also often frustrated when faced with having to implement this form of course delivery (Gambescia \& Paolucci, 2009). They are typically willing to promote OL in order to garner its financial and image-related benefits, typically viewing OL as a panacea to their problems (Wilson, 2001). However, they have found it difficult to marshal the financial, human, and technological resources required to produce high-quality learning material for online courses (Tallent-Runnels et al., 2006). In the following section, we describe in more detail the limitations of online learning in the modern era. We also present a conceptual framework which can be used to develop a strategy to address these problems.

\section{Information and Communication Technology, Online Learning, and the Dual-Mode University}

In the 1980s, traditional universities, especially in Canada and Australia, started experimenting with newly-available educational technology (Burge, 2008; Campion, 1990; Evans \& Nation, 1993). Their need was urgent and immediate: both were large countries with vast distances between population and education centers. The challenge was to increase accessibility to 
university programs in order to stimulate economic growth and improve industrial competitiveness (OECD, 2005). As personal computer-based instruction became viable and increasingly powerful, information and communication technologies (ICTs) proliferated. As a result of such online learning implemented, the potential for widespread and transformative innovation within universities became apparent (Bates, 1995, 2005; Evans \& Nation, 1993). Yet, in retrospect, this potential has not been fully realized (Guri-Rosenblit, 2009; Zemsky \& Massy, 2004).

Undergraduate OL has already emerged as a noticeable trend over the past two decades (Allen \& Seaman, 2008). However, the overall aim has, typically, been to free up space on campus, boost student enrolments, and achieve lower per-unit costs. In pursuing these objectives, OL has come to be viewed as a way of subsidizing costly on-campus instruction (Thompson, 2005). However, it has also been plagued by a reputation for low quality and, mostly for this reason, been resisted by university faculty (Zemky \& Massy, 2004; Guri-Rosenblit, 2009). Faculty attitudes towards OL are discussed by Power (2009) in a series of case studies, revealing that faculty view OL in its asynchronous form as being unsustainable, because it takes too much time to design and develop courses. Furthermore, it requires that faculty spend long hours typing on a keyboard, a task several view as "boring," "hell," and wasted time (Power, 2009). Others emphasize the futility of investing in high-level, upfront course design because frequent redesign is required (Twigg, 2003). Yet, despite this and again reinforcing the fundamental paradox that is OL, faculty in dualmode universities will likely have to become major OL providers in light of a widening gap between supply and demand in HE (Daniel et al., 2009; Olcott, 2008). Indeed, according to GuriRosenblit (2009),

The new technologies have actually turned dual-mode provision into a leading model in most HE institutions worldwide, as many conventional universities decided to adopt them for offering various forms of distance education through online provision. Many studies indicate that the future belongs to dual-mode institutions which are likely to thrive in the coming decade. (p. 126)

\section{A Critique of Distance Education, Online Learning, and Blended Learning}

As noted, a key reason DE/OL have not gone mainstream is low-level commitment from faculty. Indeed, the impetus for creating the British Open University (BOU) was a strong political will to break the monopoly of the upper-class-dominated established institutions. The BOU's explicit mission was, and continues to be, to make higher education in the UK more accessible (Perry, 1976). As a result, a dichotomy of choices appeared: either a student studied on campus or at a distance. However, when traditional universities (TUs) in Australia and Canada started adopting DE on a large scale (Evans \& Nation, 1993), these institutions began a metamorphosis and became dual-mode universities (DMUs), thereby opening up more options for students. The advent of OL deepened this trend, multiplying OL models and offerings (Guri-Rosenblit, 2009; 
Power, 2005; 2008a). Yet still, core faculty remain aloof from OL as they have from DE, thus severely limiting program offerings.

Blended learning (BL) was consolidated in the latter years of the '90s as a trade-off between completely on-campus and completely online courses (Garrison \& Kaunuka, 2004; Garrison \& Vaughan, 2008; Mortera-Gutierrez, 2006). The University of Lancaster's definition of BL is adopted here: BL occurs "where traditional forms of teaching and learning (i.e., classrooms, books, etc.) are used in conjunction with e-learning to deliver the full student experience" (see www.uclan.ac.uk/information/services/sss/quality/glossary_of_terminology.php). Usually an administration-led strategy, BL has allowed universities to rapidly-with little investmentenhance their enrolment capacity by having students spend one week on campus and one week online at home (Pullen \& Snow, 2007). BL has generally been viewed positively by faculty because it has created economies which enable them to reduce and or better manage their workload (Garrison \& Vaughan, 2008; Mortera-Gutierrez, 2006). Students also appear to see benefit in BL. Like faculty, they often view it as capable of freeing them from their weekly schedule of on-campus courses without any noticeable loss in quality (Rovai \& Jordan, 2004). However, since BL requires that students spend at least some amount of time on campus, it cannot be successful in solving the accessibility dilemma for the typical, off-campus DE student. Rather, by being marketed to students as a flexibility enhancement initiative, it has mostly been seen as a new way for administrators to expand university enrolments (Cook, Owston, \& Garrison, 2004).

\section{Addressing Accessibility, Quality, and Cost-Effectiveness in Online Learning}

In this section, we shift emphasis from understanding why distance education and the current form of OL have not met expectations and consider how a new form of DE/OL might be implemented to simultaneously increase accessibility, improve quality, and enhance costeffectiveness in HE at the graduate level. This is a problem that Kanuka \& Brooks (2010) have considered unsolvable: "[D]istance education can achieve any two of the following: flexible access, quality learning experience and cost-effectiveness - but not all three at once” (p. 69).

Sir John Daniel, a pioneer of DE, also emphasizes the virtual impossibility of universities simultaneously attaining these three goals by referring to them as the "Iron Triangle" (Daniel, Kanwar, \& Uvalic-Trumbic, 2009). He suggests that the sides of a hypothetical triangle could be considered to represent the key vectors of university course delivery: access, quality, and cost. From a strategic standpoint, Daniel considers that such a triangle has two characteristics. First, it may be distorted in different ways. Distortions represent trade-offs amongst the three key elements. Second, the triangle has a fixed-length perimeter. In practice, this means, for example, that one can only increase access to a given course under circumstances where one lowers its level of quality. Such a zero-sum view of service delivery gives rise to the reference to "iron." Daniel then argues that DE is a way of breaking out of the iron triangle, because it lowers cost while maintaining quality and increasing accessibility. As a result, the overall fixed-length perimeter can be extended, allowing the accessibility and quality sides of the triangle to be extended without a corresponding increase in the size of the cost vector. According to Daniel, DE 
allows for improvements in accessibility and quality, as well as economies of scale that traditional universities simply cannot attain. In Figure 1, a graphic representation of Daniel's thesis is presented.

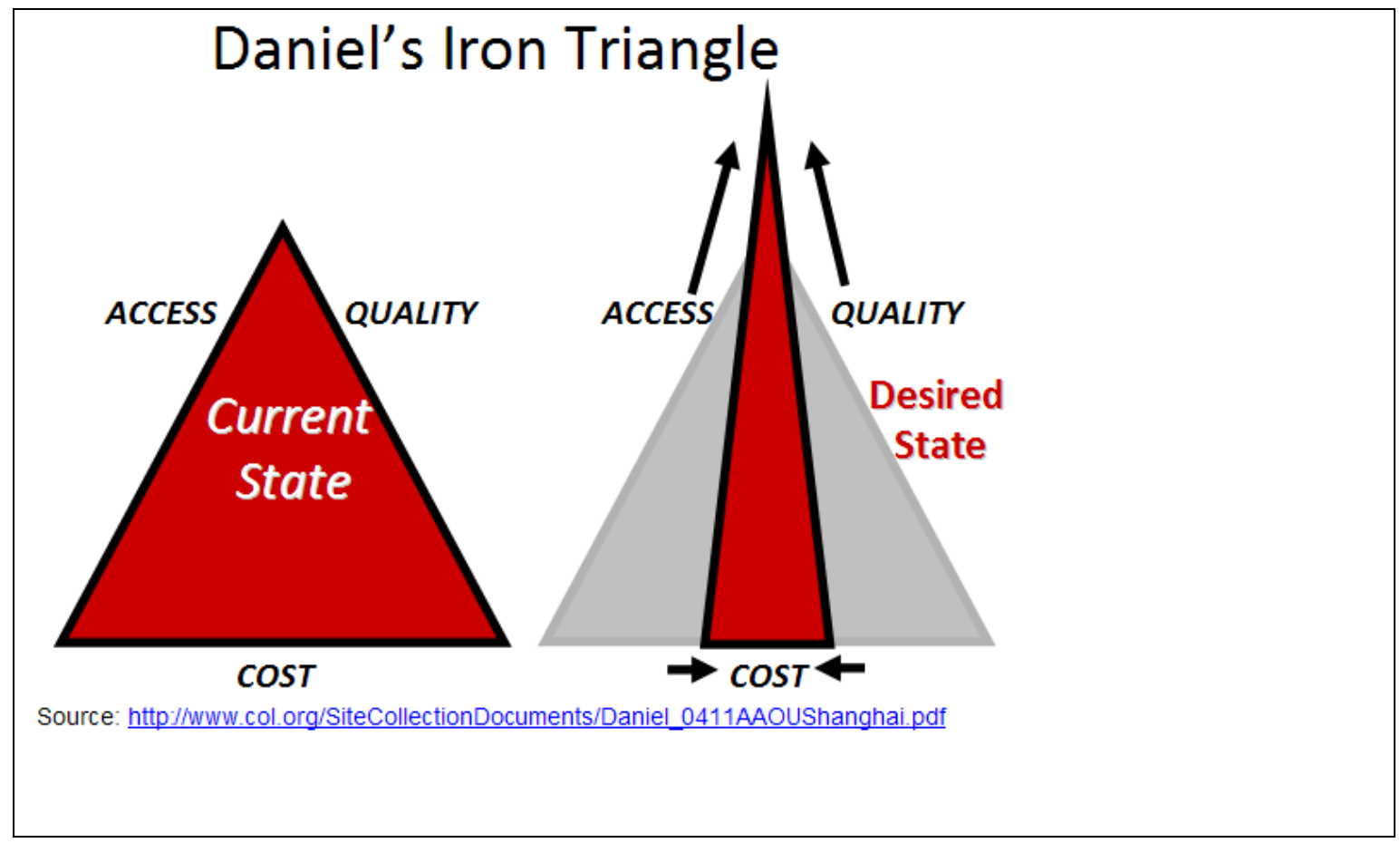

Figure 1. Daniel's iron triangle, presenting both the current state of affairs and the desired state made possible by universities implementing wide-scale distance education.

As noted earlier, despite high growth in the 1970s and 1980s, DE has not been adopted by mainstream universities (Bates, 2005). Indeed, from its outset, DE has been vigorously resisted by faculty in traditional universities (Perry, 1976). Now, under its new guise as OL, DE has only been partially and begrudgingly embraced by regular university faculty (Mitchell \& Geva-May, 2009). In light of these trends, we view Daniel's iron-triangle framework as dated and fundamentally unworkable, an industrial solution in a post-industrial period. Indeed, the iron triangle theory implicitly suggests that universities will inevitably evolve of their own accord to embrace DE/OL, because taking such a step liberates universities from the zero-sum paradigm. Yet this has not occurred. In short, had DE been such an obviously viable solution, it would likely already have been implemented.

It is therefore necessary, in our view, to understand why stakeholders have not broken out of Daniel's Triangle, when doing so seems so predictable and so beneficial to all. To address this problem, we have expanded upon the triangle concept. Our conceptualization presents OL as a strategic choice associated with defined benefits. It also considers obstacles to the transition process from a stakeholder perspective. We believe there is indeed a way out of the iron triangle which does involve OL-but it is not OL as we currently know it. In the following section, we 
will argue in favour of a form of OL that meets or exceeds the needs and expectations of key stakeholders in HE: faculty, students, and administrators.

\section{Revisiting the Iron Triangle}

As mentioned above, Daniel speaks of three vectors as the sides of the iron triangle: access, quality, and cost. Yet he does not associate vectors with specific stakeholders' groups, nor does he discuss how the needs of faculty, students, and administrators may differ. Research suggests that there are specific stakeholder groups and that they are likely not equally interested in each of Daniel's vectors (Duderstadt, Atkins, \& Van Houweling, 2002; Kampov-Polevoi, 2010; Schullo et al., 2005). We introduce the term priorities as an alternative to Daniel's vectors to take this phenomenon into account. This change in terminology emphasizes that the points of the triangle are influenced by who, in the teaching and learning processes, is assessing the situation.

Figure 2 represents our revision of Daniel's iron triangle concept, in which we propose two major changes. Firstly, as indicated above, we replace vectors with priorities, and, secondly, we modify the names of these priorities. Hence, cost is removed as a vector and replaced with costeffectiveness as a priority, namely because cost-effectiveness is seen as being a more complete and significant indicator than is cost alone. By doing this, we have three positives or elements that would be beneficial to increase, rather than two positives and a negative (i.e. in Daniel's view, that cost must be decreased). This change thereby allows us to work with positives alone, thereby making our analysis more transparent. We also do this in order to portray cost as a necessary ingredient in the DE/OL mix, rather than something to be avoided. Likewise, we have replaced access, which we consider too general a term, with accessibility, which we define narrowly here as the act of increasing access for students to DE/OL programs and courses.

Figure 2 presents our previously-identified priorities as the corners of a triangle. Each priority is associated with a stakeholder. In this diagram, we posit that students are naturally most concerned about accessibility. On the other hand, faculty are typically defenders of quality, whereas administrators are tasked with assuring system cost-effectiveness. We further suggest that each stakeholder group is naturally inclined to promote its own priority, thereby bringing the parties into conflict. However, we argue that for DE/OL to succeed, each stakeholder group should have its needs met to an acceptable threshold level. Our revised conceptualization of Daniel's IT concept establishes the corners of a triangle as more important than its sides. In passing, we note that the student stakeholder group may be considered as a more disembodied influence, something akin to market forces. We mention this because student needs are not always viewed as monolithic. On the other hand, for current purposes, we continue to refer to students as a stakeholder group, a term we consider most appropriate because it identifies whose priority is being considered and who is "pushing" for increased accessibility. 


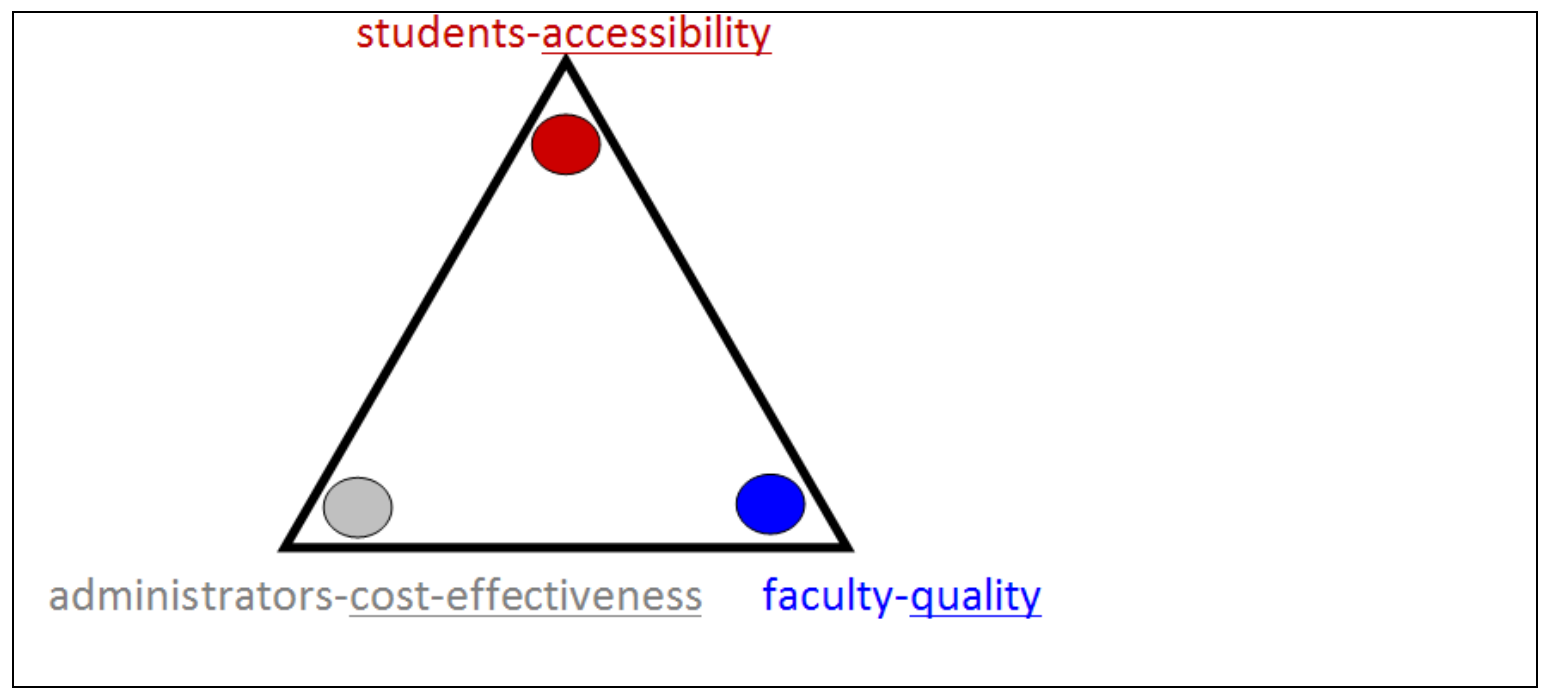

Figure 2. The Power-Gould revised iron triangle associating stakeholders and stakeholder priorities.

Figures 3A \& 3B further develop the three stakeholder - three priorities idea which is implicit in our modified iron triangle. Specifically, it indicates how parties interact to advance their agendas. For example, when students "push" accessibility (meaning that they demand access to more courses), the likelihood of "pull” at the faculty end (meaning that faculty will respond to this demand through increasing their involvement in OL) will depend on the extent to which the respective priorities of these two stakeholder grouper are in alignment. Hence, a situation is created whereby one stakeholder group will respond to the priority of another, but only insofar as such a response does not impede the pursuit of their own priority. Ideally, this dynamic would lead to a state of equilibrium and a balancing of priorities between the two stakeholder groups. However, should increasing accessibility lead to a state of worsening quality (i.e. worsening working conditions, fewer qualified students, less support for faculty, etc.), then these two stakeholder groups would have overtly non-aligned priorities, resulting in a lower probability of pull at the faculty end. Under these circumstances, we posit that faculty "pushback" would likely occur (i.e. resistance to increasing accessibility). Built into this conceptualization is the notion of a threshold, defined here as a theoretical point of equilibrium whereby all three stakeholder groups attain an acceptable level of satisfaction of their priorities. We believe that our conceptualization explains why some attempts at expanding accessibility to DE/OL in the past have failed. 


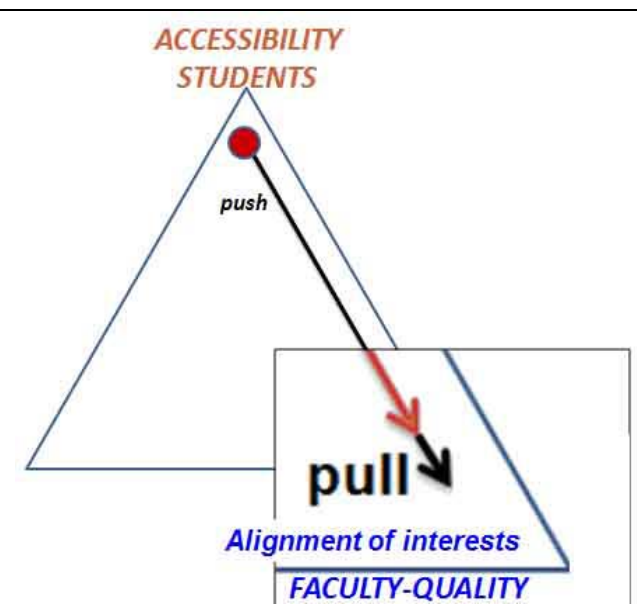

Figure 3A: Student push, faculty pull, and alignment of priorities.

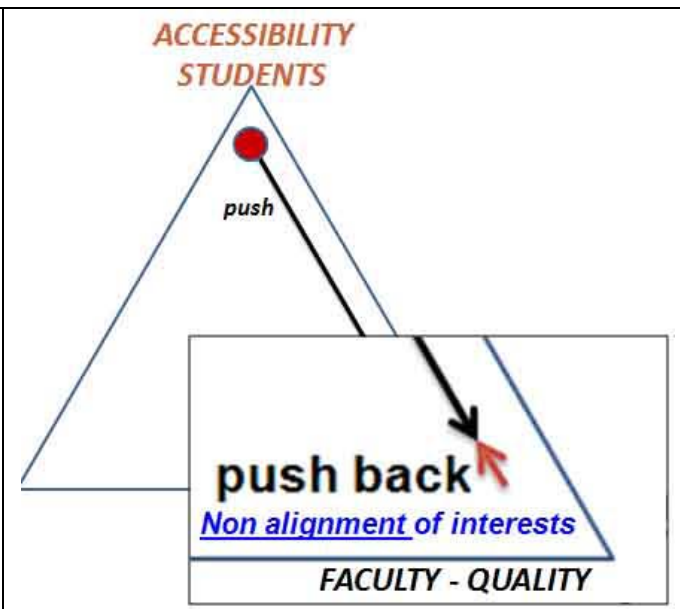

Figure 3B: Faculty push-back due to a non alignment of priorities.

The logic of Figures $3 \mathrm{~A}$ and $3 \mathrm{~B}$ can be extended to understanding the student-administration interface. This dynamic is depicted in Figures 4A and 4B. Here, one might expect administration pull as a response to a student-initiated accessibility push. Insofar as a student agenda of this kind does not impede higher levels of cost-effectiveness (C-E), such as more enrolments, higher professor-student ratios, more prepared applicants, and so on-administrators would likely accommodate this priority through a pull response. On the other hand, if increased accessibility were to lead to lesser levels of C-E (i.e., higher costs because of more services required, more upfront investment in systems or infrastructure, more faculty training, etc.), then a non-alignment of student/administrator priorities would probably emerge. Under these circumstances, administrators would likely push back in order to continue to pursue their cost-effectivenessrelated priority. Such a state of affairs would possibly result in less accessibility than desired by the student stakeholder group.

\begin{tabular}{|l|l|}
\hline STUDENTS \\
Figure 4A: Student push, administrator pull, \\
and alignment of priorities.
\end{tabular}

We also apply the logic of Figures 3A, 3B, 4A, and 4B to faculty and administrator priorities. Specifically, faculty promote (push) quality and students welcome (pull) quality, insofar as it does not interfere with their priority. Indeed, students may welcome quality in cases where it promotes accessibility and possibly heightened degree prestige. However, if accepting (pulling) quality were to lead to lower levels of accessibility (i.e., diminishing opportunities or more work), 
then students would likely react negatively (push back) in the face of overtly non-aligned priorities. Such push-back would likely be commensurate with the degree of misalignment.

An implication of our modified iron triangle is that sometimes the priorities of stakeholder groups can be somewhat broad. This state of affairs tends to create more opportunities to align priorities. For example, if faculty were to push the quality agenda and such a push coincidently led to higher levels of cost-effectiveness, (say, more prestige for their institution, better opportunities for attracting high-performing faculty, etc.), then there would likely be an enthusiastic pull of this agenda on the part of administrators. In other cases, quality might be interpreted more narrowly. For example, faculty might demand more support, more resources, or a reduced workload in order to achieve their definition of quality. Such an agenda, despite potential long-term costeffectiveness, would likely raise short-term costs and thus ultimately be unacceptable to administrators, probably resulting in a pushback from them.

Finally, to complete the analysis, were administrators to promote new cost-effectiveness measures or standards of DE/OL, there would likely be pull on the part of students, insofar as heightened C-E leads to increased accessibility. There would also likely be pull on the part of faculty, insofar as improved C-E leads to better quality. However, once again, were administrators to impose C-E measures or standards without considering their impact on accessibility and quality, then pushback would most likely ensue. Such pushback could come from one or both of the other stakeholder groups.

Unless there is an acceptable level of alignment of priorities amongst the three stakeholder groups, we posit that accessibility to HE via DE/OL will be constrained and its quality and costeffectiveness limited. Hence, we argue that alignment of priorities is the key to breaking out of the iron triangle. Our conceptualization has five key elements:

1. The three identified stakeholder groups should each be actively involved in overall DE/OL deployment. The priorities of each group should be harmoniously integrated into an overall strategy;

2. The right amount and kind of push can result in pull on the part of other stakeholders, but the key to achieving such a coordinated effort is the notion of priority or interest alignment;

3. Any major push by one of the three stakeholders will likely result in a state of disequilibrium and elicit a push-back by either one or both of the other stakeholders;

4. Priorities may be viewed broadly or narrowly by stakeholders. A broad, system-wide interpretation is likely to have greater implications for a pull reaction on the part of other stakeholders;

5. Each stakeholder group, in promoting and managing its respective priorities, should develop an understanding of and appreciation for the priorities of the other stakeholder groups. 


\section{Breaking out of the Iron Triangle}

We argue that breaking out of the iron triangle requires that $\mathrm{DE} / \mathrm{OL}$ be revised and redefined. As noted previously, for decades DE and now OL have been developed without full faculty influence. Rather, development has been mostly driven by university administrators responsible for perpetuating their institutions by promoting increased cost-effectiveness. As we have seen, faculty intent on maintaining qualitative standards have allowed this to happen, perhaps blissfully unaware of how DE and OL are fundamentally reshaping their Academy. Finally, students (i.e. market forces) are using their purchasing clout to bring about increased accessibility without necessarily considering the long-term consequences of such an agenda.

We consider that DE/OL has substantial untapped potential. Yet such potential will likely not be realized unless and until acceptable trade-offs between stakeholder priorities can be achieved. Success in doing so will translate into harmonious human and technological resource deployment, thereby creating a sustainable online teaching and learning environment. In our view, the hallmarks of this new educational environment will be sufficient ubiquity and user-friendliness to assure improved levels of accessibility; sufficient technological sophistication to allow for a quality online teaching and learning environment; and sufficient cost-effectiveness to meet university resource limitations. In the final section, we describe just such a new online teaching and learning environment that, based on current exploratory evidence-based data, balances stakeholder priorities and offers the prospect of virtually unlimited growth for universities, specifically in the field of graduate studies.

\section{Blended Online Learning Design (BOLD)}

Power (2008b, 2009) and Power \& Vaughan (2010) have described the blended online learning design (BOLD) in earlier publications. In a nutshell, BOLD is a combination of BL (blended learning) and OL. It implements a fully online, combined synchronous- and asynchronous-based learning environment with advanced knowledge-sharing and -creation tools. This hybrid online environment allows users access to a community learning experience as well as 24/7-accessible resources. A BOLD course brings graduate students and faculty together on a regular basis in real time, to debate, critique, and consult one another-implementing both spontaneous and differed modes of learning. In Figure 5, BOLD unites the synchronous, dialogue-based tradition of the campus-based university and the asynchronous, structure-based tradition of the distance education university (Power, 2002; Power \& Vaughan, 2010). 


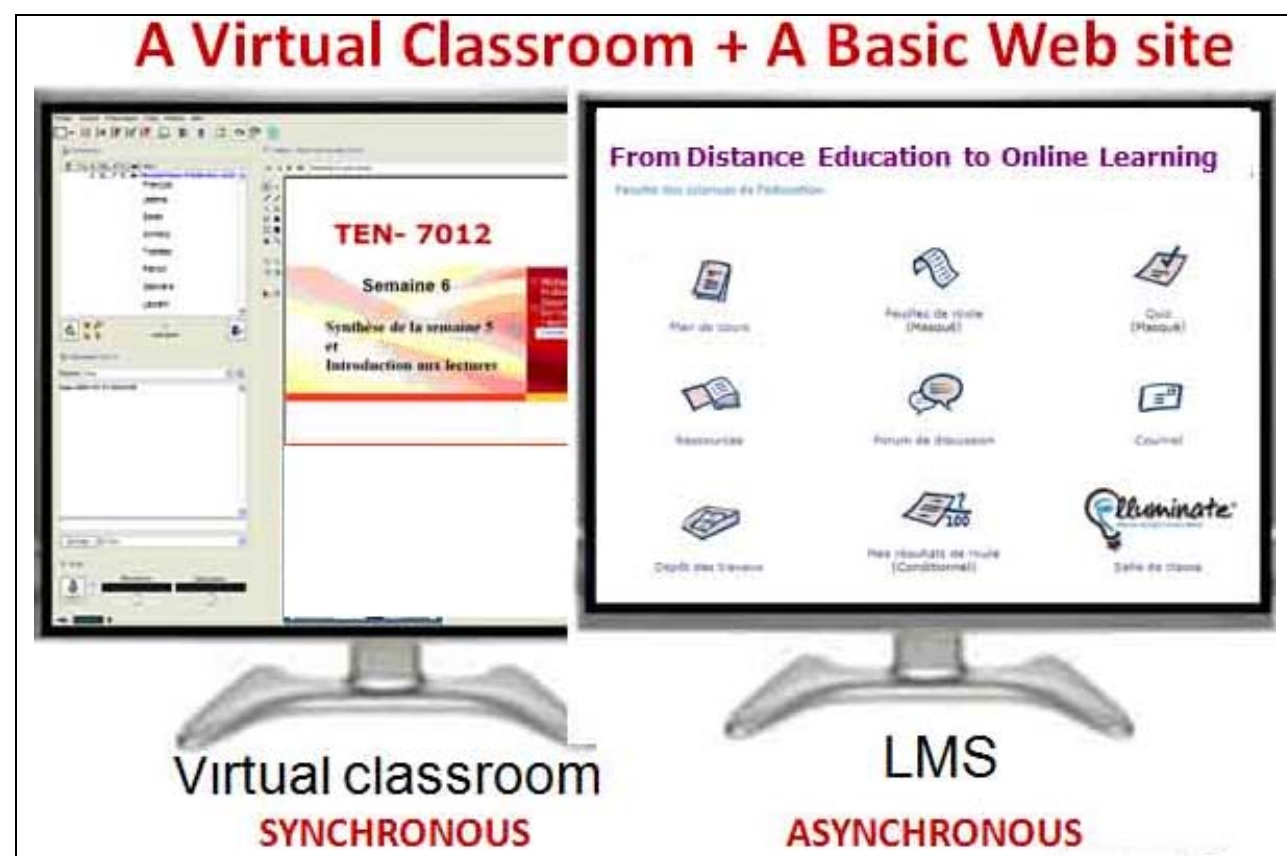

Figure 5. BOLD, a combined-technology approach to the design and delivery of university graduate studies.

BOLD emphasizes the fundamental need for a combination of, on the one hand, a basic, userfriendly learning management system (LMS) and, on the other, a virtual classroom (a.k.a. a synchronous desktop conferencing platform). As such, BOLD can be seen as bridging both asynchronous and synchronous forms of instruction, thereby creating a new form of OL. This new space for OL is illustrated in Figure $6{ }^{1}$. Here, various university-level design and delivery models are situated on a Cartesian plane. They are differentiated according to their teaching mode (synchronous or asynchronous) and their design and delivery mode (on-campus versus online). Figure 6 embodies several ideas. In its lower left-hand quadrant, traditional $H E$ is located. This strategy is the perennial, mainstream, on-campus design and delivery and professor-led, processbased, synchronous-mode teaching. To the right of traditional HE is videoconferencing. This mode of teaching stretches towards the "online space" (in implementing technology) but is also campus-based because it uses satellite campuses. Hence, it is depicted in Figure 6 as straddling the line. Above, traditional HE are library-type resources, which represent course-associated materials that are not available online but are generally accessed asynchronously on campus. In the upper right-hand quadrant, online learning is located. This is characterized by a systemmanaged, product-based, asynchronous teaching mode in the DE tradition. As such, it is seen as being the antithesis of traditional HE. On the other hand, blended learning is a form of teaching that combines both campus-based and OL activities. It is depicted in Figure 6 as a trade-off model, in that it draws on and amalgamates some of the strengths of other design and delivery modes while having the weakness (for off-campus learners) of still requiring some degree of student presence on campus. Finally, BOLD is located in the entire right half of the diagram. This mode is characterized by an optimal blend of, on the one hand, synchronous and asynchronous

\footnotetext{
${ }^{1}$ For a more complete explanation of Figure 6, please see Power, 2008a.
} 
activities and, on the other, faculty-led and system-led activities. It must be emphasized that BOLD is very much a trade-off model, in that it allows for spatial freedom (reaching out to offcampus learners) but not for temporal freedom (in that seminars are scheduled at set times, as they are on campus).

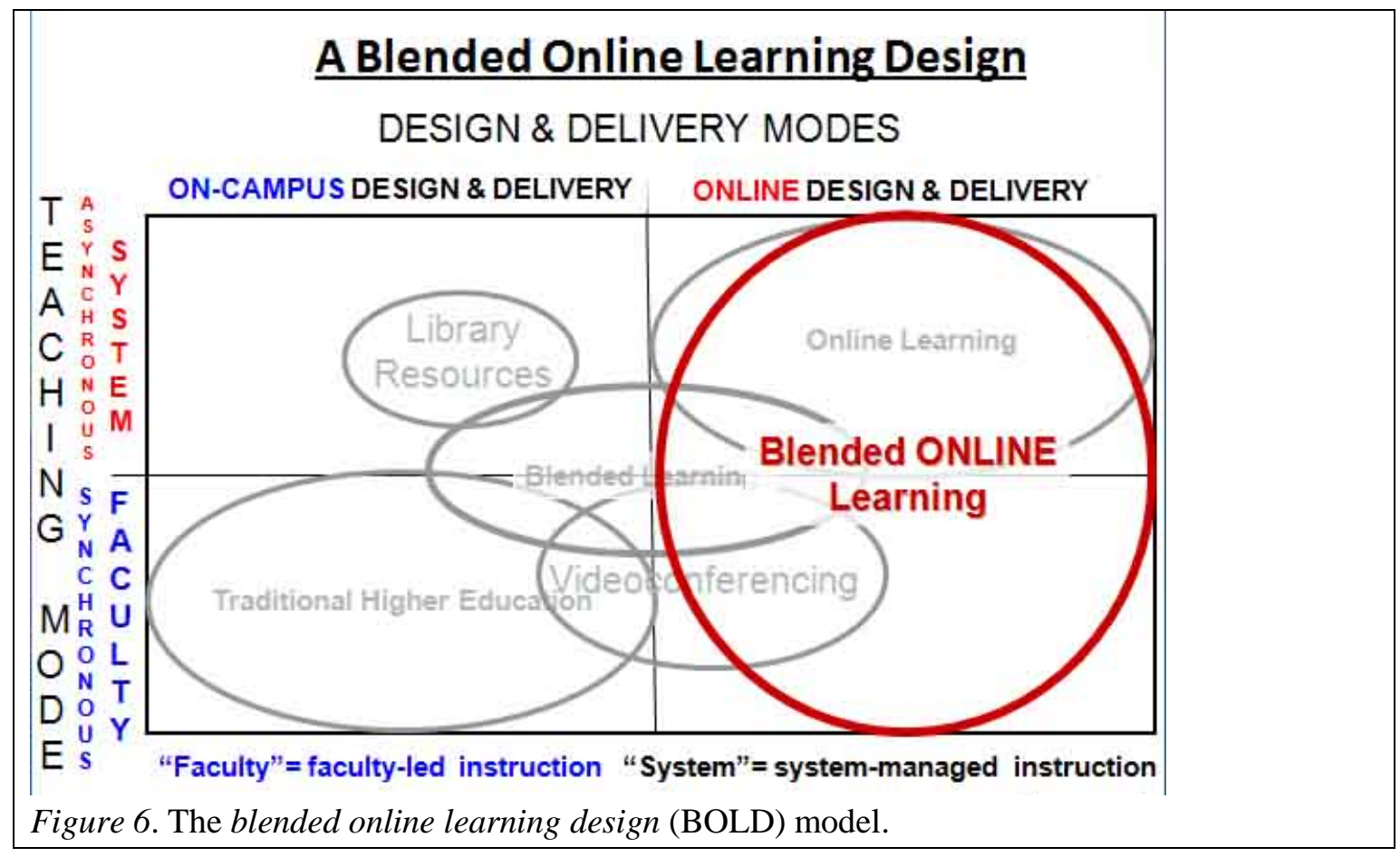

As we have seen previously, Traditional Universities (or TUs), whether they implement DE, OL, or BL, fail to address at least one and, at times, two of the three stakeholder priorities to an acceptable threshold level, thereby resulting in limited successful deployments of alternative course delivery modes. BOLD, on the other hand, appears to better harmonize the priorities of all three stakeholder groups, based on current data (Power \& Vaughan, 2010). It overcomes the shortcomings of DE, OL and BL in the following ways:

- BOLD offers a higher level of accessibility to graduate seminars than those offered by TUs implementing BL, in that students attend a BOLD seminar completely online. It thus achieves enhanced spatial freedom for both faculty and students by removing the oncampus requirement. Student accessibility is further enhanced through access to recordings of weekly classes whenever and as often as they like. This is especially important in the case of second-language students (Moore \& Kearsley, 2005). Faculty experience a pull reaction to BOLD in that they can work with students wherever they may be located geographically. Indeed, faculty report that BOLD-enhanced accessibility allows them to maintain teaching commitments while taking advantage of increased opportunity for off-campus research and fieldwork, making BOLD highly attractive to them. Administrators also experience a pull reaction vis-à-vis BOLD because, using already available infrastructure (existing institutional computer network and faculty equipment) and offsetting expenses (students use their equipment and their own Internet 
connection), they can increase enrolments without any "bricks-'n-mortar” investment, thereby achieving increased cost-effectiveness. In a nutshell, from an economic perspective, administrators are quick to realize that increased accessibility allows traditionally low-enrolment graduate courses to quickly become viable.

- Compared to DE and OL, BOLD improves quality, because faculty find transition to a BOLD environment more engaging and rewarding than to DE (increased level of dialogue with students) and less taxing than to OL (less front-end design, hence less time commitment and less effort). Some even allude to "higher touch" (proximity to students) while simultaneously experiencing "higher tech" (state-of-the-art virtual classroom), concepts once considered diametrically opposed (Naisbitt, Naisbitt, \& Philips, 2001). BOLD thus represents a trade-off between the costly front-end design associated with asynchronous OL courses and the highly inaccessible TU classroom-based seminars. It strikes this balance because real-time, online dialogue compensates for lower front-end design. Hence, faculty are reporting that designing and developing a BOLD course requires a similar time commitment to a TU seminar. As we have seen, such equivalence is achieved thanks mostly to the synchronous component. But the asynchronous component - a basic course website - also contributes to it. Leaner than that of a standalone OL course, the website is developed and updated on an ongoing basis by faculty, but often supplemented by the graduate students themselves. Increased quality is also reported in reference to dialogue in the virtual classroom which successfully approximates the on-campus experience. Students report pull as they are given the opportunity to interact in real-time with their professors and peers, a benchmark for quality in TUs. BOLD, as opposed to DE/OL, affords them a more quality experience and, as opposed to $\mathrm{BL}$, they have the "group experience" without having to come to a university campus. Students also report that gaining access to previously unavailable seminars improves the overall quality of their programs and degrees. Moreover, faculty who implement BOLD report experiencing less of a workload as compared to teaching asynchronous OL courses, while enjoying a similar level of direct interaction with students (compared to TU seminars). Finally, administrators also report pull, not only because of heightened student satisfaction levels, but also because of increased core faculty engagement with OL and added prestige to their institution for effectively contributing to outreach, factors that augur well for future large-scale OL deployment.

- BOLD also seems to improve cost-effectiveness in that it requires no substantial investment or costly incentive system. It enables administrators to "top up" lowenrolment seminars, or even launch entirely new ones as they would TU seminars, on a per-demand basis. BOLD requires much lower start-up costs (due to lower front-end design levels and on-the-fly enrolment) than rival approaches (DE, OL, and BL) and creates expanded outreach possibilities (any online student who accepts the temporal limitation can enrol). Moreover, as the potential pool of students expands, possibilities emerge for offering seminars or full programs for which there may be little or even no local demand, but for which substantial national or international demand exists. By maintaining on-campus course scheduling (courses are "slotted" in the same way they are 
for TU seminars) and faculty workloads (a BOLD course is accounted for in the same way as a regular seminar), administrators avoid the pitfalls commonly associated with OL. These include the issues of faculty transition to OL, hiring adjunct faculty, and providing high-level technical support for faculty. Furthermore, BOLD removes intellectual property as an obstacle to faculty online engagement because, simply put, there is none, as such. Faculty, in launching a BOLD course, use the virtual classroom as they would their campus classroom. They interact in real-time with their graduate students. Such interaction does not produce intellectual property which may be contested. BOLD courses focus on processes and on human resource deployment (like TU seminars) rather than on products and costly didactic material design and delivery (as is common in DE-OL). In 2010, content is no longer king (Odlyzko, 2001) or as much of an issue as it was in 1994, when OL started. Virtually unlimited resources are now available online, waiting only to be harnessed by faculty and students alike. Hence, faculty implement BOLD to teach an augmented form of their TU seminars enhanced by online resources, a form of delivery that may be described as an augmented webinar. Each course is as unique as any TU seminar. Its nature and character are influenced by the issues raised and discussed synchronously or asynchronously, or both, as well as by the personalities and idiosyncrasies of graduate students as well as their professors.

\section{Conclusion}

Further research is required to ascertain with any degree of certitude the applicability of blended online learning design (BOLD) in various situations. Indeed, a number of international pilot projects are currently underway. When completed, these will shed more empirical light on the theory presented in this article. In the meantime, we consider that BOLD offers enormous potential in meeting the needs of faculty, students, and administrators because it harmonizes disparate priorities. A strategic perspective on these issues is timely because the sector has grown rapidly but, at this stage, with mixed results and, at times, lacklustre support from key stakeholders.

This paper has focused on blending synchronous- and asynchronous-mode teaching and learning strategies and technologies in higher education. We have argued that BOLD has the potential to enhance accessibility while maintaining quality and cost-effectiveness in graduate studies. Results may interest faculty, administrators, and instructional designers, as well as educational researchers who are engaged in TU teaching, learning, DE, OL, or BL research. BOLD represents a departure from the DE-inspired, industrial-based, single-mode university instructional design model still prevalent in asynchronous-mode, online learning today and proposes, in its stead, a post-industrial, faculty practice-related, dialogue-rich design model. We deem BOLD a more suitable model for dual-mode universities than rival strategies. It brings together separate but complementary conceptual frameworks, such as distance education, online learning, blended learning, faculty development, instructional design, and educational technology. 


\section{References}

Allen, I. E. and Seaman, J. (2008). Staying the course: Online education in the United States. Needham, MA: Sloan Consortium.

Anderson, T. (Ed.). (2008). Theory and practice of online learning. Athasbasca, AB: Athabasca University.

Bates, A. (1995). Technology, open learning and distance education. London/New York: Routledge.

Bates, A. (2005). Technology, e-learning and distance education. London/New York: Routledge.

Bedford, L.A. (2009). The professional adjunct: An emerging trend in online instruction. Online Journal of Distance Learning Administration, 12 (3). Retrieved from http://www.westga.edu/ distance/ojdla/browsearticles.php

Berge, Z. \& Huang, Y. (2004). A model for sustainable student retention: A holistic perspective on the student dropout problem with special attention to e-learning. DEOSNEWS, 13 (5). Retrieved from http://www.ed.psu.edu/acsde/deos/deosnews/deosnews13_5.pdf

Bertrand, L. (2009). Réinventer l'université. Québec, QC: Presses de l’Université Laval.

Blin, F. \& Munro, M. (2008). Why hasn't technology disrupted academics' teaching practices? Understanding resistance to change through the lens of activity theory. Computers \& Education, 50, 475-490.

Bok, D. (2003). Universities in the marketplace: The commercialization of higher education. Princeton, NJ: Princeton University Press.

Bullen, M. \& Janes, D. (Eds.). (2007). Making the transition to e-learning: Strategies and issues. Hershey, PA: Information Science Publishing.

Burge, L. (2008). 'Crafting the future': Pioneer lessons and concerns for today. Distance Education, 29 (1), 5-17.

Campion, N. (1990). Post-fordism and research in distance education. In T. Evans (Ed.), Research in distance education. Geelong, Australia: Deakin University.

Carr-Chellman, A. A. (Ed.). (2005). Global perspectives on e-learning: Rhetoric and reality. Thousand Oaks, CA: Sage Publications.

Collis, B. \& Moonen, J. (2002). Flexible learning in a digital world. Open Learning: The Journal of Open and Distance Learning, 1469-9958, 17(3), 217-230. 
Cook, K., Owston, R. D., \& Garrison, D. R. (2004). Blended learning practices at COHERE Universities. Institute for Research on Learning Technologies. Technical Report No. 2004-5. Toronto, ON: York University.

Daniel, S. J., Kanwar, A., \& Uvalic-Trumbic, S. (2009). Breaking higher education's iron triangle: Access, cost, and quality. Change, March-April,

Dreyfus, H. L. (2001). On the internet. London: Routledge.

Duderstadt, J. J., Atkins, D. E., \& Van Houweling, D. (2002). Higher education in the digital age: Technology issues and strategies for American colleges and universities. Connecticut: Greenwood Publishing.

Evans, T., \& Nation, D. (1993). Reforming open and distance education. London: Kogan Page.

Gambescia, S. F. \& Paolucci, R. (2009). Academic fidelity and integrity as attributes of university online degree program offerings. Online Journal of Distance Learning Administration, 12(1), Spring. $\quad$ Retrieved from http://www.westga.edu/ distance/ojdla/spring121/gambescia121.html

Garrison, D. R. (2009). Implications of online learning for the conceptual development and practice of distance education. Journal of Distance Education/Revue de l'éducation à distance, 23(2), 93-104.

Garrison, D. R., \& Vaughan, N. (2008). Blended learning in higher education. San Francisco: Jossey-Bass.

Garrison, D. R., \& Archer, W. (2007). A community of inquiry framework for online learning. In M. Moore (Ed.), Handbook of distance education (pp. 77-88). New York: Erlbaum.

Garrison, D. R., \& Kanuka, H. (2004). Blended learning: Uncovering its transformative potential in higher education. Internet and Higher Education, 7, 95-105.

Guri-Rosenblit, S. (2009). Digital technologies in higher education: Sweeping expectations and actual effects. New York: Nova Science.

Harasim, L., Hiltz, S. R., Teles, L., \& Turoff, M. (1995). Learning networks: A field guide to teaching \& learning online. Cambridge: MIT Press.

Kampov-Polevoi, J (2010). Considerations for supporting faculty in transitioning a course to online format. Online Journal of Distance Learning Administration, 13(2). 
Kanuka, H. \& Brooks, C. (2010). Distance education in a post-fordist time: Negotiating difference. In M. F. Cleveland-Innes \& D. K. Garrison (Eds.), An introduction to distance education: Understanding teaching and learning in a new era. New York \& London: Routledge.

Ludwig-Hardman, S. \& Dunlap, J. C. (2003). Learner support services for online students: Scaffolding for success. The International Review of Research in Open and Distance Learning, 4(1). Retrieved from http://www.irrodl.org/index.php/irrodl/article/view/131/602

Maeroff, G. I. (2003). A classroom of one: How online learning is changing our schools and colleges. New York: Palgrave Macmillan.

Maguire, L. L. (2005). Literature review-Faculty participation in online distance education: Barriers and motivators. Online Journal of Distance Learning Administration, 8(1). Retrieved from http://www.westga.edu/ distance/ojdla/spring81/maguire81.htm

Mitchell, B. \& Geva-May, I. (2009). Attitudes affecting online learning implementation in higher education institutions. Journal of Distance Education/Revue de l'éducation à distance, 23(1), 71-88.

Moore, M. G. \& Kearsley, G. (2005). Distance education. A systems view (2nd ed.). Belmont, CA: Thomson Wadsworth.

Morgan, C. K. \& Tam, M. (1999). Unravelling the complexities of distance education student attrition. Distance Education, 1475-0198, 20(1), 96-108.

Mortera-Gutiérrez, F. (2006). Faculty best practices using blended learning in e-learning and face-to-face instruction. International Journal on E-Learning, 5(3), 313-337. Chesapeake, VA: AACE.

Naisbitt, J., Naisbitt, N., \& Philips, D. (2001). High tech/high touch: Technology and our accelerated search for meaning. London: Nicholas Brealey Publishing.

Noble, D. F. (2001). Digital diploma mills: The automation of higher education. New York: Monthly Review Press.

OECD (2005). E-learning in tertiary education: Where do we stand? Paris: OECD, Centre for Educational Research and Innovation.

Odlyzko, A. (2001). Content is not king. First Monday, 6(2-5). Retrieved from http://firstmonday.org/htbin/cgiwrap/bin/ojs/index.php/fm/article/view/833/742 
Olcott, D. (2008, November). Going global: Opportunities and challenges for open and distance learning. ACU Conference of Executive Heads, Hyderabad, India.

Orr, R., Williams, M. R., \& Pennington, K. (2009). Institutional efforts to support faculty in online teaching. Innovative Higher Eucation, 34(4),

Perry, W. (1976). Open university: A personal account by the first vice-chancellor. Milton Keynes, UK: The Open University Press.

Pittinsky, M. S. (Ed.). (2003). The wired tower: Perspectives on the impact of the internet on higher education. Upper Saddle River, NJ: Prentice Hall.

Power, M. \& Vaughan, N. (2010). Redesigning online learning for international graduate seminar delivery. Journal of Distance Education/Revue de l'éducation à distance, 24(2). Retrieved from http://www.jofde.ca/index.php/jde/issue/view/59

Power, M. (2009). A designer's log: Case Studies in instructional design. Athabasca, AB: Athabasca University Press. $\quad$ Retrieved from http://www.aupress.ca/index.php/books/120161

Power, M. (2008a). The emergence of blended online learning. Journal of Online Learning \& Teaching, 4(4). Retrieved from http://jolt.merlot.org/vol4no4/power_1208.htm

Power, M. (2008b). A dual-mode university instructional design model for academic development. International Journal for Academic Development, 13(1), 5-16. Retrieved from http://dx.doi.org/10.1080/13601440701860185

Power, M. (2005). Le design pédagogique dans un contexte de bimodalisation de l'enseignement supérieur: Une étude multi-cas. Faculté des sciences de l'éducation, Université Laval. Unpublished doctoral dissertation. Retrieved from http://www.theses.ulaval.ca/2005/23258/23258.html

Power, M. (2002). Générations d'enseignement à distance, technologies éducatives et médiatisation de l'enseignement supérieur. Journal of Distance Education/Revue de l'éducation à distance, 17(2). Retrieved from http://www.jofde.ca/index.php/jde/article/view/115

Pullen, J. M. \& Snow, C. (2007). Integrating synchronous and asynchronous internet distributed education for maximum effectiveness. Education and Information Technologies, 12, 137-148.

Rovai, A. P. \& Jordan, H. M. (2004). Blended learning and sense of community: A comparative analysis with traditional and fully online graduate courses. International Review of 
Research in Open and Distance Learning, 5(2). Retrieved from http://www.irrodl.org/index.php/irrodl/article/view/192/274

Sammons, M. C. \& Ruth, S. (2007). The invisible professor and the future of virtual faculty. International Journal of Instructional Technology and Distance Learning, 3(1),

Schullo, S., Barron, A. E., Kromrey, J. D., Venable, M., Hohlfeld, T., \& Hogarty, K. Y. (2005, April). Enhancing online courses with synchronous coftware: An analysis of strategies and interactions. Annual Meeting of the American Educational Research Association, Montreal, Canada.

Shea, P., Fredericksen, E., Pickett, A., Pelz, W.. (2005). Increasing access to higher education: A study of the diffusion of online teaching among 913 college faculty. International Review of Research in Open and Distance Learning, 6(2). Retrieved from http://www.irrodl.org/index.php/irrodl/article/view/238/493

Tallent-Runnels, M. K., Thomas, J. A., Lan, W. Y., Cooper, S., Ahern, T. C., Shaw, S. M., et al. (2006). Teaching courses online: A review of the research. Review of Education Research, 76(1), 93-35.

Thompson, K. (2005). Constructing educational criticism of online courses: A model for implementation by practitioners. Unpublished doctoral dissertation. University of Central Florida: Orlando, FL.

Twigg, C.A. (2003). Improving learning and reducing costs: New models for online learning. EDUCAUSE Review, 38(5), 29-38.

U.S. Department of Education (2010). Evaluation of evidence-based practices in online learning: A meta-analysis and review of online learning studies. Office of Planning, Evaluation, and Policy Development: Washington, D.C. Retrieved from http://www.ed.gov/rschstat/eval/tech/evidence-based-practices/finalreport.pdf

Vonderwell, S. (2003). An examination of asynchronous communication experiences and perspectives of students in an online course: A case study. Internet and Higher Education, 6(1), 77-90.

Wilson, G. (2001). The promise of online education: El dorado or fool's gold? Educational Technology Journal, 11(1).

Zemsky, R. \& Massy, W.F (2004). Thwarted innovation. What happened to e-learning and why? Retrieved from http://www.irhe.upenn.edu/Docs/Jun2004/ThwartedInnovation.pdf 


\section{Athabasca University $\mathbf{Z}$}

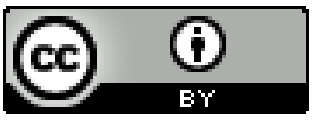

